\title{
RESEARCH
}

\section{"Blasts" from the Past: Lung Cancer in Cape Breton}

\author{
S. MacCormick BSc', F Cragg MD², K Hussain MD², Ron MacCormick MD² \\ ${ }^{1}$ Trinity College Dublin, Ireland \\ ${ }^{2}$ Cape Breton Regional Hospital, Sydney, Nova Scotia, Canada
}

\begin{abstract}
Background: With the advent of molecular testing and its role in determining appropriate therapy for non small cell lung cancer (NSCLC), particularly adenocarcinoma, we reviewed charts from the Cape Breton Cancer Centre from 2011 to 2013, to determine availability of tissue for molecular testing. We were also interested in recording the distribution of histologic subtypes of NSCLC in this population.
\end{abstract}

Methods: A detailed chart review was carried out exploring relative rates of various histologies, smoking history, type of diagnostic procedure carried out, availability of tissue for further testing, and need for re-biopsy. When necessary for diagnostic clarification, pathology review was done.

Results: For convenience and to prevent selection bias, one hundred consecutive lung cancer cases coded as NSCLC by the provincial cancer registry were reviewed. The highest percentage was squamous cell $(40 \%)$, followed by adenocarcinoma (29\%), NSCLC not otherwise specified (18\%), large cell (6\%), neuroendocrine (4\%), and adenosquamous (3\%). These figures are out of line with typical North American figures and are similar to findings from the 1950s and 1960s.

Conclusion: This study demonstrated more than expected squamous cell NSCLC and less adenocarcinoma. Environmental and lifestyle issues may be implicated. With recent environmental changes and the enactment of an anti-smoking bylaw in Cape Breton, we expect to see these figures change to those more typical for North America.

In past studies by Health Canada, the Cape Breton region (Nova Scotia, Canada) demonstrated significantly higher cancer mortality in both men and women compared to the rest of Canada. ${ }^{1}$ Because of this finding, there have been a variety of cancer control efforts in Cape Breton over the last two decades.

Lung cancer is the second most common cancer in both male and female Canadians, after prostate cancer and breast cancer, respectively. ${ }^{2}$ In 2013, lung cancer represented $13.8 \%$ of new cancer cases in males and $13.3 \%$ of new cancer cases in females. ${ }^{2}$ Non-small cell-lung cancer (NSCLC) makes up the majority of lung cancer cases in North America representing $85-90 \%$ of all lung cancers. ${ }^{3}$ NSCLC is comprised of three main subtypes: adenocarcinoma, squamous cell carcinoma and large cell lung cancer. According to the American Cancer Society, adenocarcinoma represents the majority (40\%) of the NSCLC subtypes. ${ }^{3}$ This has not always been the case. Thirty years ago squamous cell histology was most common, but adenocarcinoma has surpassed squamous cell in the last 20 years. ${ }^{4}$
Treatment options for NSCLC have traditionally been quite limited. Surgery and radiation therapy for earlydetected disease is associated with reasonable cure rates. ${ }^{3}$ However, treatment of advanced disease is mainly limited to the use of modestly beneficial chemotherapy, but is associated with considerable toxicity. ${ }^{3}$

In order to improve outcomes in advanced NSCLC, systemic therapy must be improved. Traditional chemotherapy is somewhat limited in its ability to induce tumor regression and improve overall survival. Various molecular targets have been identified that can be exploited with newer targeted therapies. ${ }^{5}$ These molecular targets have been primarily identified to be effective predictors of treatment response in adenocarcinoma but not in other histologic subtypes. ${ }^{5}$ One example of this is epidermal growth factor receptor mutation (EGFR), or over-expression. Such a finding leads to improved response rate and improved overall survival when inhibitors of EGFR are employed. ${ }^{6}$ A similar improvement in outcome has been observed when anaplastic lymphoma kinase (ALK) rearrangements are identified. This rearrangement 
occurs in only $4 \%$ of patients with adenocarcinoma but its identification is important. ALK mutation patients can benefit from the targeted agent crizotinib with minimal toxicity. ${ }^{6}$ A caveat, however, is that molecular testing can be expensive (often exceeding $\$ 1000$ per panel of tests). ${ }^{7}$

We reviewed the charts of 100 consecutive patients referred to the Cape Breton Cancer Centre from 2011 to 2013. One hundred consecutive patients were picked for convenience, investigator time restrictions, and an attempt to eliminate selection bias. Our initial intent was to identify whether these patients had adequate tissue available to do molecular testing, and to determine the distributions of various sub-types of NSCLC in this patient population.

When looking at sub-types of NSCLC, our hypothesis was that we would find a distribution of tissue types similar to the rest of North America, i.e. adenocarcinoma as the most common type.

\section{Methods}

After our research protocol was approved by our local research ethics board (REB), a summer student was hired to review charts and pathology reports of 100 consecutive Cape Breton patients identified and referred to the Cape Breton Cancer Centre with a diagnosis of NSCLC. The Nova Scotia Cancer Registry was utilized for identification of these patients during the period 2011 to 2013 . The charts of these 100 patients were reviewed in regards to various demographic characteristics, occupation, smoking history, stage at diagnosis, biopsy procedure, pathology, primary treatment and outcomes. Particular attention was paid to availability of tissue for molecular testing. When pathology reports gave an uncertain diagnosis, the tissue samples were reviewed with the reporting pathologist. Comparison between the observed proportions of adenocarcinomas and squamous cell carcinomas, and those reported previously in the literature was done by performing one-sample test of proportions, using the binomial approximation to the normal distribution. All tests were done in a two-tailed manner, with a 95\% level of confidence.

\section{Results}

Table 1 is in keeping with Canadian Cancer Registry Data, in that NSCLC is more common in men and those with a heavy smoking history. ${ }^{2}$ Our cohort however had a lower percentage of lung cancer patients who had never smoked (5\%) compared to Canadian Data (15\%). Stage at diagnosis is also in keeping with Canadian Cancer Registry data. The high number of patients alive at the time of review is in keeping with their recent diagnosis.

Gender Number of patients

\begin{tabular}{lc}
\hline Male patients & 55 \\
Female patients & 45 \\
Smoking history & 5 \\
Never smoked & 12 \\
$<10$ pack years & 80 \\
> 10 pack years & 3 \\
Unknown & \\
Survival status at time of review & 77 \\
Alive & 23 \\
Deceased & \\
Cancer stage & 28 \\
I & 11 \\
II & 34 \\
III & 24 \\
IV & 3 \\
Unknown & \\
\hline Table 1. Demographics of 100 patient NSCLC cohort (2011-2013)
\end{tabular}

In North America, published literature reveals that adenocarcinoma makes up roughly $40 \%$ of all lung cancer. $^{3}$ Table 2 indicates that adenocarcinoma represented only $29 \%$ of all lung cancers. The observed proportion of adenocarcinomas is statistically different from the expected proportion of the same ( $\mathrm{P}=0.03,95 \%$ CI, 0.206 to 0.391 ).

\begin{tabular}{lc} 
Cancer diagnosis & Number of patients \\
\hline Squamous cell & 40 \\
Adenocarcinoma & 29 \\
NOS & 18 \\
Large cell & 6 \\
Neuroendocrine & 4 \\
Adenosquamous & 3 \\
Total & 100 \\
\hline Table 2. Pathologies of lung cancer patients from 100 patient cohort
\end{tabular}


Similarly in North America, literature shows that squamous cell carcinoma should make up roughly $25 \%$ of all lung cancers. ${ }^{3}$ In our study, squamous cell carcinoma represented $40 \%$ of all lung cancers. The difference between the observed proportion and the expected proportion was statistically significant $(\mathrm{P}=0.001 ; 95 \% \mathrm{CI}, 0.305$ to 0.503$)$.

Therefore, in this particular cohort (Cape Breton Island), squamous cell carcinoma is not only more prevalent than adenocarcinoma, but also more prevalent than the expected range of squamous cell carcinoma for the rest of the country. ${ }^{2}$ Conversely, adenocarcinoma is far less prevalent than expected.

This is an unusual finding in Canada. However, similar irregularities have been identified in the United Kingdom in 2008 where squamous cell carcinoma was found to be more prevalent than adenocarcinoma. ${ }^{8}$ This analysis was of patients diagnosed from 1995 to 2004 which is an earlier cohort than our study population. Within this United Kingdom cohort, the increased prevalence of squamous cell histology was associated with increased "social deprivation". Interestingly, in England smoking prevalence increased with socioeconomic deprivation. ${ }^{9}$

\section{Discussion}

Lung cancer is the leading cause of cancer related deaths in Canada, accounting for $26.5 \%$ of all cancerrelated mortalities in $2013 .^{2}$ Prior to the National Cancer Institute of Canada (NCI-C) study by Rapp and colleagues, published in 1988, the primary therapy for advanced NSCLC was radiation therapy and supportive care. ${ }^{10}$ This NCI-C study demonstrated a modest survival benefit of approximately two to three months with platinum based chemotherapy versus best supportive care (BSC). Since this landmark paper, survival benefits with newer chemotherapy regimens has remained fairly static. ${ }^{11}$

More recently with the advent of newer targeted therapies, potentially more effective and less toxic treatment regimens are emerging. ${ }^{5}$ Currently the most promising targets include the ALK-fusion protein, and both mutations and overexpression of EGFR. ${ }^{12}$ When ALK-fusion protein is identified, treatment with the protein kinase inhibiter crizotinib has been associated with response rates of $65 \%$ as compared to $20 \%$ for standard chemotherapy. ${ }^{13}$

Studies of the use of EGFR inhibitors has also demonstrated that response rates in patients with unknown EGFR status is less than 10\% while response rates in patients with known EGFR mutation or over expression is greater than 30\%. ${ }^{14}$ Interestingly, these targets are more often seen in adenocarcinomas than other histologies, particularly squamous cell histology. ${ }^{15}$

Given this set of circumstances, we felt that it was important to get a sense of the potential demand for molecular testing for the community of Cape Breton Island. We wanted to know the percentage of our NSCLC patients who had adenocarcinoma and therefore might benefit from further molecular testing.

As an aside, in a report by Yang Mao in 1983, Cape Breton was identified as having an excess of $19 \%$ for male cancer mortality and an excess of $13 \%$ for female cancer mortality when compared with the rest of Canada. ${ }^{1}$ This disturbing figure has lead to various cancer control efforts in Cape Breton over the last 20 years.

Our study demonstrated an unexpected finding: Cape Breton had a signficiantly higher proportion of squamous cell histology than adenocarcinoma. Could

\begin{tabular}{llc} 
Tissue Type & Biopsy procedure & Number of patients \\
\hline Cytology & Transthoracic FNA & 61 \\
& Pleurocentesis & 1 \\
Histology & Bronchoscopy & 27 \\
& Lobectomy & 7 \\
& Thoracoscopy & 3 \\
& VATS Wedge Resection & 1 \\
& Total number of biopsies & 100 \\
\hline
\end{tabular}

Table 3. Source of original diagnostic biopsy material at time of lung cancer diagnosis 100 patient NSCLC cohort (2011-2013) 


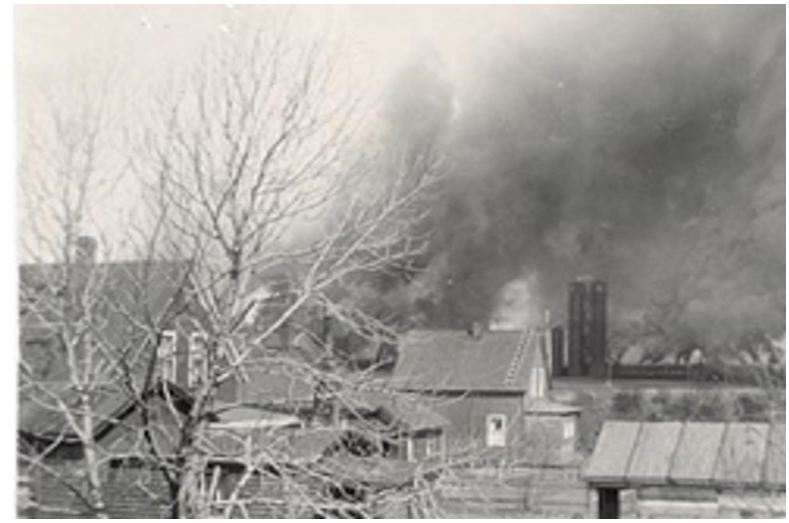

Picture 1. Cape Breton Airshed circa 1970

there be an easy explanation for the over-representation of squamous cell cancer in Cape Breton?

Squamous cell differentiation in NSCLC is felt to be more commonly seen in areas with a high particulate load in the ambient airshed and in heavy smokers. ${ }^{16}$ Sydney, Cape Breton's largest city, was host to the Sydney Steel Plant throughout the 20th century. This plant was situated in the middle of the most densely populated area of the city. From the opening of the Sydney Steel Plant in 1901 until the shut down of the plant's blast furnace in 1988, there were over a million tons of particulate matter vented into the Sydney airshed. ${ }^{17}$ Local residents vividly recall the bright orange sunsets and also having to clean iron ore resiude off their car windshields every morning (see picture 1 and 2).

A provincial report by Pierre Lavigne in 1997 revealed that Cape Bretoners had the highest rates of smoking in the province. ${ }^{6}$ Our cohort demonstrated a lower percentage of "never smoked" then expected. These two points, i.e. increased particulate matter in the airshed and higher smoking rates, could explain the higher than expected squamous cell histology. Since 1988, there have been two major efforts that may ultimately decrease cancer incidence in Cape Breton, particularly squamous cell lung cancer. The first was converting from a blast furnace to make steel to an electric arc furnace in 1988. The second was the implementation of a very comprehensive public places anti-smoking bylaw in 2002. ${ }^{18}$ These two measures have led to a marked improvement in the particulate matter in the Sydney airshed. ${ }^{19}$

In regards to the future, we do expect to see the relative rate of squamous cell histology to adenocarcinoma decrease. It's been 26 years since the closure of the Sydney Steel blast furnace and 13 years since the

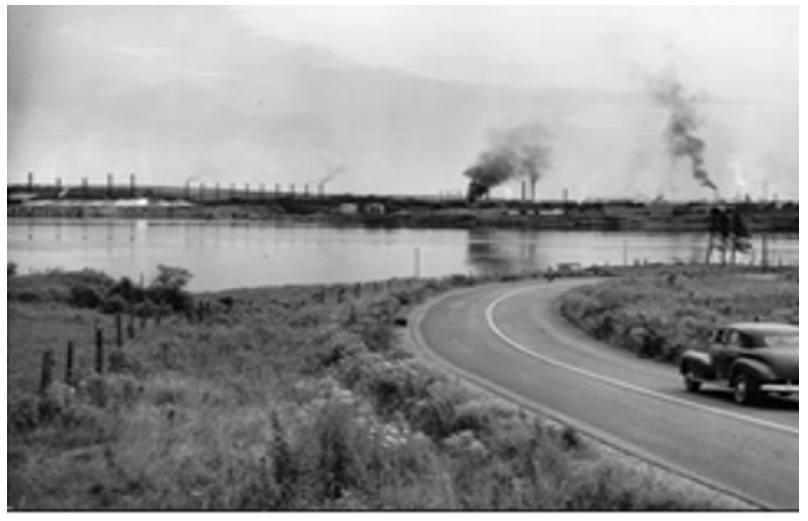

Picture 2. View of Sydney Steel Plant from across Sydney Harbour

implementation of the Cape Breton anti-smoking bylaw. Typical latency period between exposure to a carcinogen and development of lung cancer is 30 years. ${ }^{20}$ This prediction and its testing makes Cape Breton and particularly Sydney an ideal epidemiologic lab.

A follow-up to this study is planned in five years time. We expect to see the relative rates of squamous cell carcinoma to adenocarcinoma decrease. This would be more reflective of the rest of North America. But as of now our lung cancer situation continues to reflect the environment of Cape Breton until closure of the Sydney Steel Blast furnace: essentially, a 'blast' from the past.

\section{References}

1. Mao Y, Morrison H, Semenciw R. Mortality in Cape Breton, Nova Scotia, 1971-1983. Chronic Diseases in Canada Special Report No. 11. Health and Welfare Canada, 1985.

2. Canadian Cancer Society's Advisory Committee on Cancer Statistics. Canadian Cancer Statistics 2013. Toronto, ON: Canadian Cancer Society; 2013.

3. National Cancer Institute. "Lung Cancer (Non-small Cell)." 20 Jan 2015.< http://www.cancer.org/cancer/lungcancer-non-smallcell/ detailedguide/non-small-cell-lung-cancer-what-is-non-smallcell-lung-cancer> (14 Aug. 2013).

4. Vincent, RG, Peckren J Wental. The changing histopathology of lung cancer: a review of 1682 cases. Cancer 1977;39(4):1647-.

5. Leighl, NB. Treatment Paradigms for Patients with Metastatic Non-small-cell Lung Cancer: First-, Second-, and Third-line. Current Oncology 2012;19(Suppl 1): S52-S58. http://dx.doi. org/10.3747/co.19.1114

6. Lavigne, Pierre M. A Report on the Cape Breton Risk Factor Survey. Nova Scotia: Nova Scotia Department of Health, 1987:142.

7. Adamson RT. Biomarkers and molecular profiling in nonsmall cell lung cancer: an expanding role and its managed care implications. Am J Manag Care 2013; 19 (19 Suppl): S398-404.

8. Bennett VA, Davies EA, Jack RH, Mak V, Møller H. Histological sub type of lung cancer in relation to socio-economic deprivation in South East England. BMC Cancer 2008; 8:139.

9. Cancer Research UK. "Lung cancer incidence statistics." 20 Mar 2014. <http://www.cancerresearchuk.org/cancer-info/ cancerstats/types/lung/incidence/uk-lung-cancer-incidence- 
statistics> (15 Aug 2013).

10.Rapp E, Pater JL, Willan A, Cormier Y, Murray N, Evans WK, et al. Chemotherapy can prolong survival in patients with advanced non-small-cell lung cancer-report of a Canadian multicenter randomized trial. J Clin Oncol. 1988;6(4):633-41.

11. Schiller JH. Current standards of care in small-cell and non-smallcell lung cancer. Oncology 2001; 61(Suppl 1):3-13. http://dx.doi. org $/ 10.1159 / 000055386$

12. Ionescu D. N. Impact of the College of American Pathologists, the International Association for the Study of Lung Cancer, and the Association for Molecular Pathology Clinical Practice Guidelines for EGFR and ALK Testing in Lung Cancer in Canada." Current Oncology 2013;20(4):220-26. http://dx.doi.org/10.3747/ co. 20.1568

13. Shaw A, Kim D, Nakagawa K, Seto T, Crinó L, Ahn, MJ, et al. Crizotinib versus Chemotherapy in Advanced ALK-positive Lung Cancer. N Engl J Med 2013;368(25);2385-94. ttp://dx.doi. org/10.1056/nejmoa1214886

14. Paez JG, Jänne PA, Lee JC, Tracy S, Greulich H, Gabriel S, et al. EGFR Mutations in Lung Cancer: Correlation with Clinical Response to Gefitinib Therapy. Science 2004;304(5676):14971500. http://dx.doi.org/10.1126/science.1099314.

15. Mok TS, Wu Yl, Thongprasert S, Yang CH, Chu DT, Saijo N, et al. Gefitinib or carboplatin-paclitaxel in pulmonary adenocarcinoma. N Engl J Med 2009;361(10):947-57. http://dx.doi.org/10.1056/ nejmoa0810699

16. College of American Pathologists. "Lung cancer - Squamous cell Carcinoma." <www.cap.org/apps/docs/reference/myBiopsy/ LungSquamousCellCarcinoma.pdf > (3 Sept. 2013).

17. Lambert TW, Guyn L, Lane SE. Development of local knowledge of environmental contamination in Sydney, Nova Scotia: environmental health practice from an environmental justice perspective. Sci Total Environ. 2006; 368(2-3):471-484. http:// dx.doi.org/10.1016/j.scitotenv.2006.03.012

18. Nova Scotia House of Assembly. "Acts of 2012." Smoke-free Places Act. 2007. <nslegislature.ca/legc/statutes/smokfree.htm> (15 Aug 2013).

19. Amed Earth \& Environment Limited. "Ambient air monitoring program 2001 Annual Summary Report, Muggah Creek Remediation Project, Sydney, NS. Final Report." Aug 2002. < http://www.tarpondscleanup.ca/ stpa/upload/reports/AMEC-2. pdf $>$ (15 Aug 2013).

20. Weiss W. Cigarette smoking and lung cancer trends. A light at the end of the tunnel?. Chest. 1997; 111(5):1414-16. http://dx.doi. org/10.1378/chest.111.5.1414

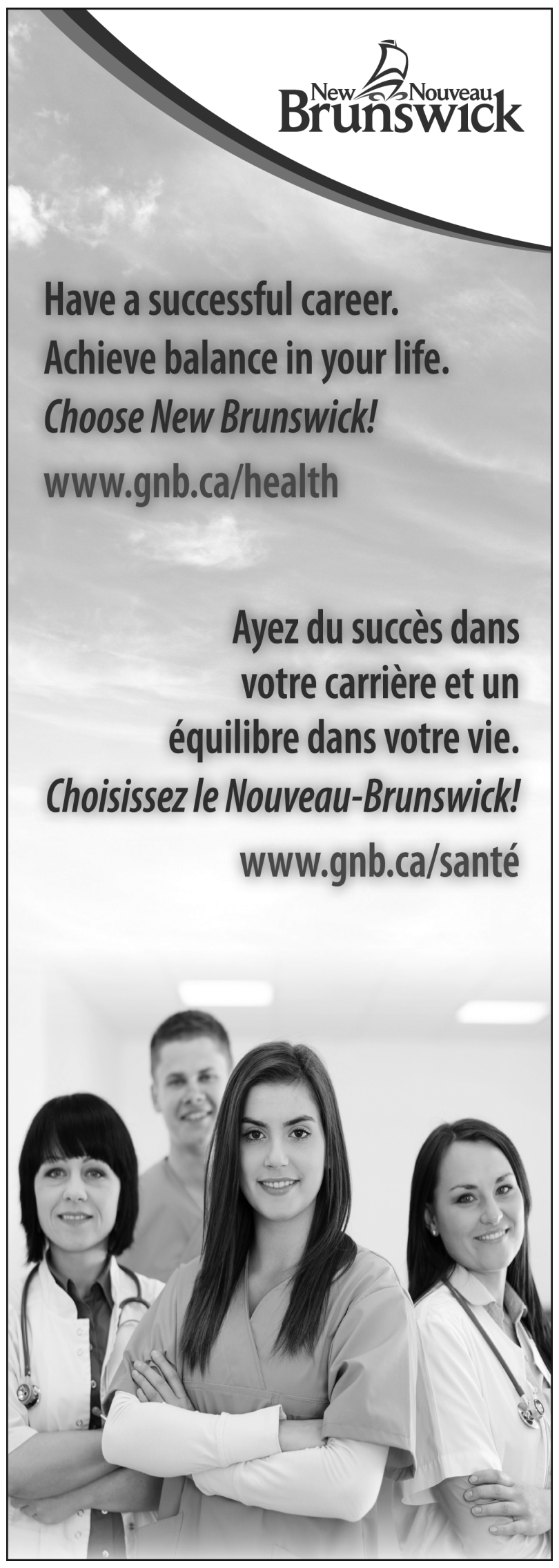

